\title{
Erratum to: Fission fragment distributions within dynamical approach
}

\author{
K. Mazurek ${ }^{1, a}$, P.N. Nadtochy ${ }^{2}$, E.G. Ryabov ${ }^{3}$, G.D. Adeev ${ }^{3}$ \\ 1 Institute of Nuclear Physics Polish Academy of Sciences, PL-31342 Krakow, Poland \\ 2 Omsk State Technical University, Mira prospekt 11, Omsk, 644050, Russia \\ ${ }^{3}$ Omsk State University, Physics Department, Mira prospekt 55-A, Omsk, 644077, Russia
}

Original article: Eur. Phys. J. A (2017) 53: 79, DOI: 10.1140/epja/i2017-12262-1

\section{Received: 17 May 2017}

Published online: 30 June 2017

(c) The Author(s) 2017. This article is published with open access at Springerlink.com

After publication, the authors realized that eqs. (1) and (14) were not correct and mistakes were present in the text on p. 13.

The correct formula for eq. (1) is

$$
\rho_{s}^{2}(z)= \begin{cases}\left(c^{2}-z^{2}\right)\left(A_{s}+B z^{2} / c^{2}+\frac{\alpha z}{c}\right), & B \geq 0 \\ \left(c^{2}-z^{2}\right)\left(A_{s}+\frac{\alpha z}{c}\right) \exp \left(B c z^{2}\right), & B<0\end{cases}
$$

and for eq. (14) it is

$$
\mathrm{d} K=-\frac{\gamma_{K}^{2} I^{2}}{2} \frac{\partial V}{\partial K} \mathrm{~d} t+\gamma_{K} I \sqrt{\mathrm{d} t \frac{T}{2}} \xi(t)
$$

On p. 13, left column, " $\nu_{0} 0.15 \times 10^{-21} \mathrm{MeV} \mathrm{s} \mathrm{fm}^{-3}$ " and " $\nu_{0} 0.125 \times 10^{-21} \mathrm{MeV} \mathrm{s} \mathrm{fm}{ }^{-3}$ " should be, respectively, " $\nu_{0}=0.15 \times 10^{-21} \mathrm{MeV} \mathrm{s} \mathrm{fm}^{-3}$ " and " $\nu_{0}=0.125 \times 10^{-21} \mathrm{MeV} \mathrm{s} \mathrm{fm}^{-3}$ ".

The authors apologize for these mistakes and any inconvenience caused.

\footnotetext{
${ }^{a}$ e-mail: katarzyna.mazurek@ifj.edu.pl
} 